\title{
PEDESTRIAN WIND COMFORT AT THE VICINITY OF A PLANNED HIGH-RISE BUILDING WITH VARYING SURROUNDS
}

\author{
BARTOSZ KIESIEWICZ, ALEKSANDER PISTOL \& ANDRZEJ FLAGA \\ Wind Engineering Laboratory, Cracow University of Technology, Poland
}

\begin{abstract}
Evaluation of pedestrian wind comfort around new developments has become crucial when planning erections of high-rise buildings, with many countries directly requiring it for planning permissions. This paper describes a case study of a high-rise building planned in the centre of Birmingham, where rapid development requires assuming various development scenarios for the tests. Wind microclimate assessment was done according to the Lawson comfort criteria, which are considered an industry standard in the United Kingdom. This required not only measuring the mean wind velocity at each of the measuring locations but also an extreme value analysis. The basis of the assessment was wind tunnel model tests, conducted for three different development scenarios: existing development, existing development with the subject building and future development with all the planned buildings within the nearest surroundings. Including other planned skyscrapers was essential, as on the opposite side of the street one of the tallest buildings in Birmingham would be situated. Furthermore, three different seasonal circumstances were considered in the assessment: annual, summer (most time spent outside, therefore the strictest requirements) and winter (most harsh weather conditions). Pedestrian wind comfort was evaluated at about 80 measuring points, located along the main transit pathways and recreational spaces in the proximity of the development. A total of 18 wind direction sectors were included in the tests, with meteorological data taken from the Birmingham Airport station. The obtained results showed that a slight decrease of wind comfort was observed at certain locations, but not too severe and the adjusted development still fit within the assumed criteria, both in terms of comfort and safety. A variety of parameters chosen for the analysis - different development scenarios and weather conditions - allowed for a comprehensive and robust analysis of wind comfort conditions at the site.

Keywords: wind tunnel tests, high-rise buildings, pedestrian wind comfort.
\end{abstract}

\section{INTRODUCTION}

The purpose of this research work was to evaluate the effects of the building complex The Square in Birmingham on wind microclimate of its nearest surroundings, most notably pedestrian wind comfort.

This required both meteorological data of the area and wind tunnel model tests. Wind comfort evaluation requires combining these two sets of information in order to provide a robust calculation of probability of threshold wind velocities exceedances at different location, also taking into account the proposed destination of these locations.

\section{EXPERIMENTAL SETUP}

\subsection{Subject of model tests}

The subject of wind tunnel model tests is building complex located at Land at Ryland Street, Broad Street and Grosvenor Street West, Birmingham, United Kingdom (later referred herein as The Square). The location of the site is shown in Fig. 1.

The Square consists of two lower buildings, which are topped by a high rise building. The building dimensions are as follows: 
- Building A: $111 \mathrm{~m}$ tall, $46.4 \times 17.1 \mathrm{~m}$ in plane

- Building B: $20.6 \mathrm{~m}$ tall, $60.3 \times 17.6 \mathrm{~m}$ in plane

- Building C: $26.5 \mathrm{~m}$ tall, $54.2 \times 15.3 \mathrm{~m}$ in plane

The scheme of the complex, with each of the buildings indicated, is shown in Fig. 2. Wind tunnel tests are mostly focused on the tallest Building A, which largely alters its surroundings and might have a significant impact on the wind microclimate in the area.

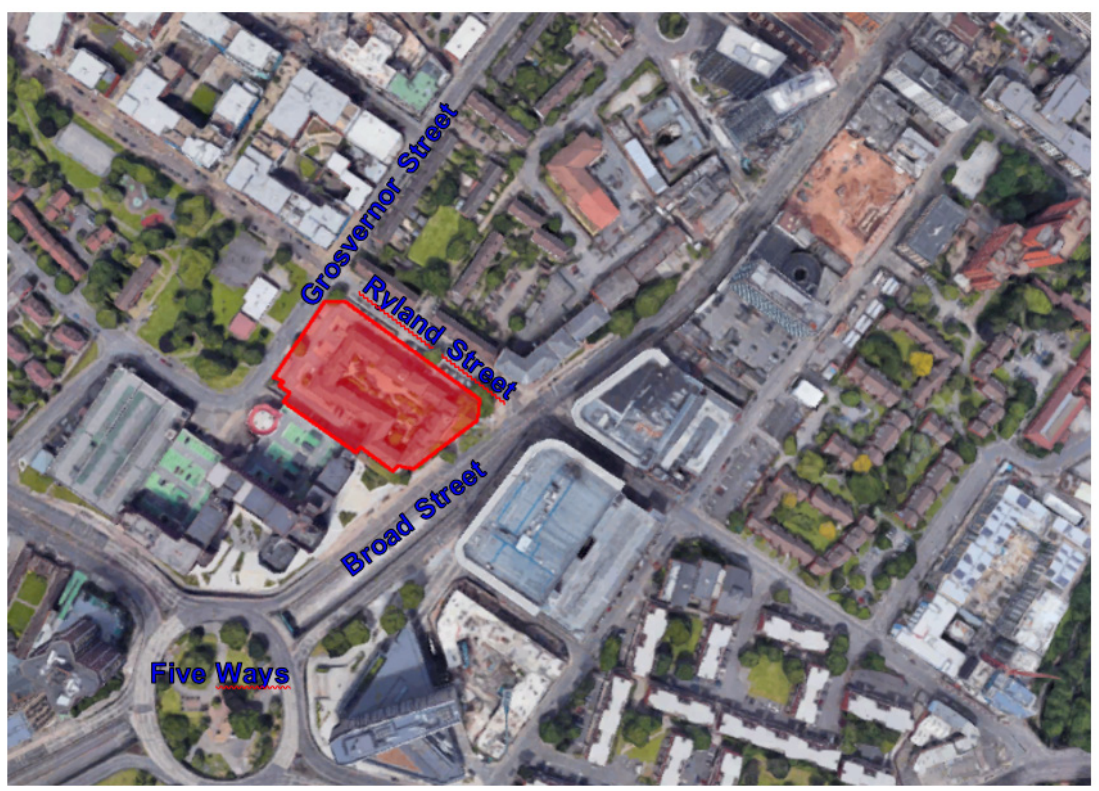

Figure 1: Satellite photo showing the building site (marked in red) and its surroundings.

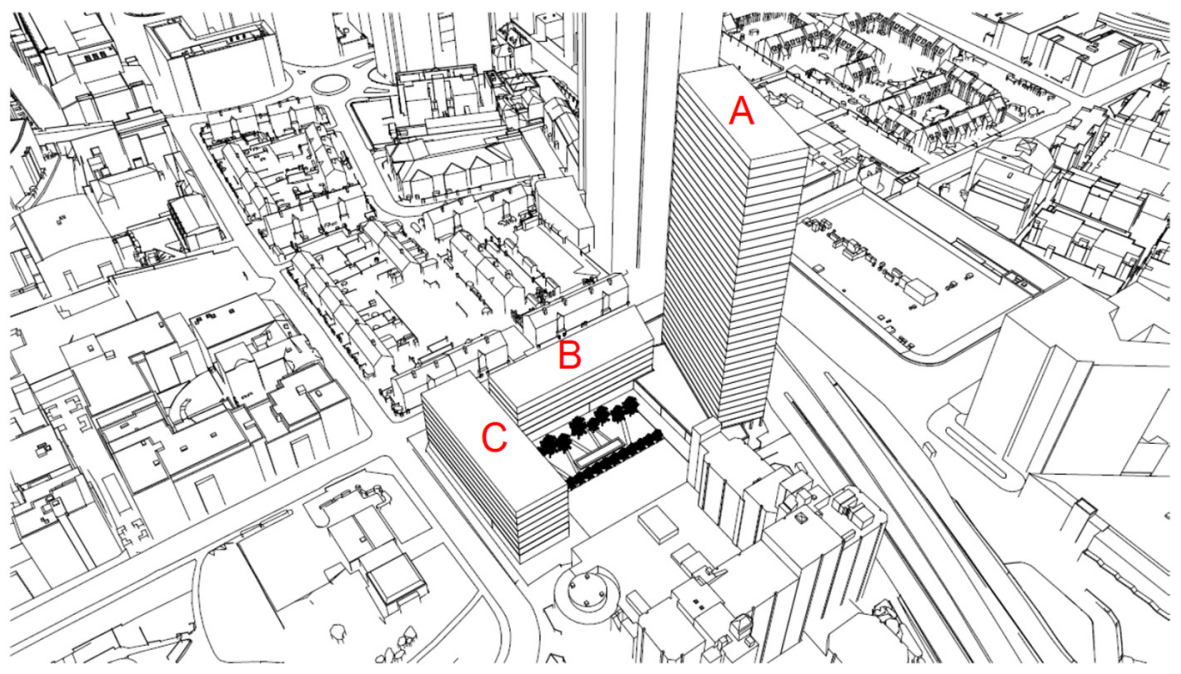

Figure 2: Scheme of proposed buildings massing with adopted indication of the buildings. 
The site is located in a central location within Birmingham City centre, along Broad Street, a main access route into and out of the city. Neighbouring buildings, along the street, include offices, hotels and retail outlets. Along Ryland Street, at the rear of the site, the area consists of houses and apartment blocks. Along Bishopsgate Street the area consists of malls and houses. Along route A46 there is a multi-level intersection.

In close vicinity of the site there are other high-rise buildings - both already erected and approved. This list includes:

- Left Bank Tower: 71 and $102 \mathrm{~m}$ tall, located about $210 \mathrm{~m}$ to the north-east of the site

- One Hagley Road: $69 \mathrm{~m}$ tall, located about $160 \mathrm{~m}$ to the south-west of the site

- Hampton by Hilton Hotel: $64 \mathrm{~m}$ tall, located about $180 \mathrm{~m}$ to the east-north-east of the site

- $\quad$ The Mercian (under construction): $132 \mathrm{~m}$ tall, located about $250 \mathrm{~m}$ to the north-east of the site

- MatchBox/211 Broad Street (approved): $117 \mathrm{~m}$ tall, located about $220 \mathrm{~m}$ to the eastnorth-east of the site

- 100 Broad Street (approved): $193 \mathrm{~m}$ tall, located about $30 \mathrm{~m}$ to the east of the site

In order to evaluate the impact of The Square building on the wind microclimate within its surroundings, three development scenarios have been investigated:

- Scenario 1: Existing development (including The Mercian, which is under construction)

- Scenario 2: Existing development with The Square building complex included

- Scenario 3: Existing development with The Square building complex and future, approved developments (100 Broad Street and MatchBox) included

\subsection{Measuring apparatus}

Model tests were conducted in the boundary layer wind tunnel of Cracow University of Technology, described in detail in Flaga et al. [1]. Wind flow velocity measurements are conducted with hot-wire anemometric system (Fig. 3), which is used for acquisition and visualisation of measurement data from ATU2001 hot-wire anemometers connected with multipurpose data acquisition module National Instruments NI-USB 6009. The cooperation between this module and hot-wire anemometers is executed by 4 analogue inputs in differential configuration.

4-channel hot-wire anemometric module is designed for velocity and temperature measurement in air flows. The set consists of complete of mono- and double-filament probes, holders that connect probes with module, data acquisition module and external power supply. The module acts as a converter of signal from probes on voltage output signals proportional to air flow velocity and temperature. It consists of four channels, each equipped with DC thermometer and DC hot-wire anemometer.

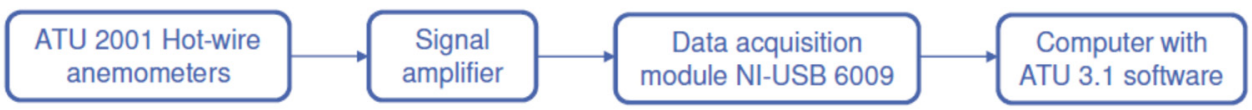

Figure 3: 4-channel hot-wire anemometric module ATU2001 - scheme of measurement path. 


\subsection{Model used for the tests}

Model tests were performed in the scale of 1:250. The adopted scale allowed for obtaining the most reliable results in the conditions of strong aerodynamic interference caused by the neighbouring tall buildings around the site. The model included the subject building and its nearest surroundings in the radius of $250 \mathrm{~m}$. The model was made on a rotating circular board $198 \mathrm{~cm}$ in diameter. Picture of the completed model (Scenario 2) inside the working section of the wind tunnel is presented in Fig. 4.

Total difference between roof level of The Square Building A (high-rise building) and the ground level of surrounding terrain is $43.8 \mathrm{~cm}$ for adopted model scale. In the surroundings of the site recreated in the model scale, there are several tall buildings: The Mercian (52.7 cm in the adopted model scale), Left Bank Towers $(40.5 \mathrm{~cm}, 28.7 \mathrm{~cm}$ in the adopted model scale), One Hagley Road (27.6 cm in the adopted model scale), Hampton by Hilton ( $25.8 \mathrm{~cm}$ in the adopted model scale), 100 Broad Street (77.2 $\mathrm{cm}$ in the adopted model scale) and MatchBox (46.8 cm in the adopted model scale). The computer visualisation of the model altered for Scenario 3, which shows every high-rise building, can be seen in Fig. 5.

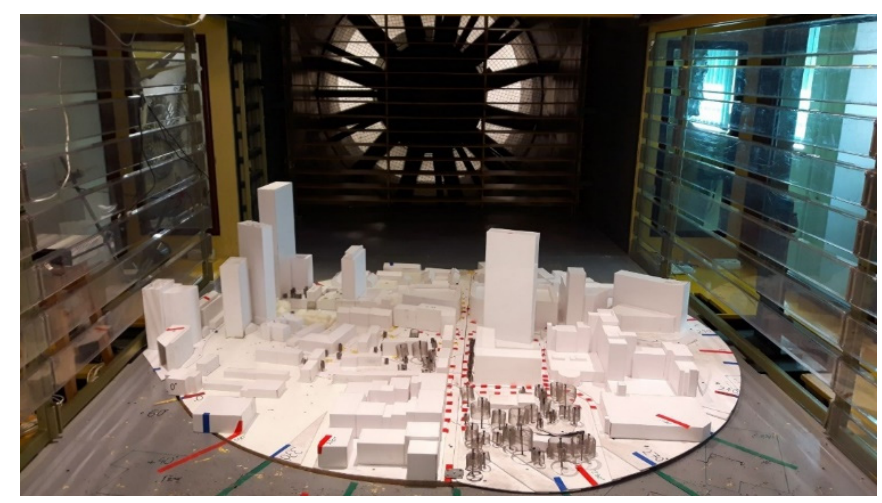

Figure 4: Model of Scenario 2 inside the working section of wind tunnel (windward view).

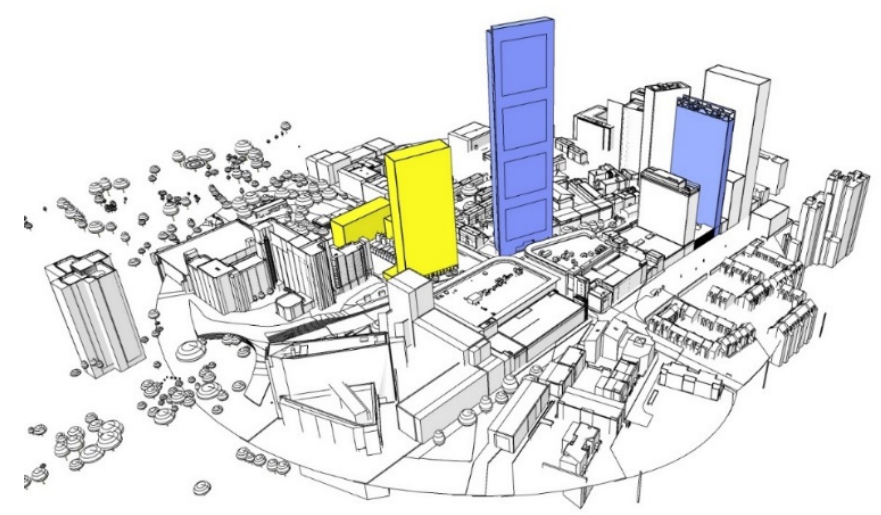

Figure 5: Computer visualisation of the model altered for Scenario 3 (The Square building complex marked in yellow, approved 100 Broad Street and Matchbox buildings marked in blue). 


\section{APPROACH TO PEDESTRIAN WIND COMFORT EVALUATION}

\subsection{Theoretical basics of the proposed approach}

Pedestrian wind comfort analysis allows for evaluation of whether pedestrians feel comfortable in windy conditions. It is based on many different factors, which can be divided into three main categories [2]:

- Meteorological: wind velocity, air temperature, humidity, sunlight, solar irradiance, cloud cover, precipitation, air pollution

- $\quad$ Physiological: age, gender, type of physical activity, clothing, chilling of body, time of exposure

- Psychological: weather expectations, health condition, mood, level of accommodation

As most of these conditions are individually developed, it is hard to construct a single type of criteria into which everyone would fit [3]. Therefore, criteria have been developed for a standard person. The factors which are in bold above have the most significant impact on the criteria taken into account in most works.

To analyse pedestrian wind comfort, one must define a threshold wind velocity $\left(V_{T R H}\right)$ and calculate the probability of exceedance of the threshold wind velocity $\left(P_{\text {exc }}\right)$. If wind velocity exceeds the threshold wind velocity people can feel uncomfortable. Nevertheless, in a pedestrian wind comfort analysis it is common to assume that comfortable wind conditions are not provided at all times [4]. The uncomfortable wind conditions may appear but only with a limited probability of exceedance. The values of threshold wind velocity as well as the probability of threshold wind velocity exceedance are summarised in respective pedestrian wind comfort criteria, taking into account the pedestrian activity.

The procedure of pedestrian wind comfort calculation [5] starts at determination of mean wind velocity at the pedestrian level $\bar{V}_{P}\left(\theta_{i}\right)$ defined for a respective angle of wind onflow $\theta_{i}$ in the measurement point. When comparing this value with the threshold wind velocity $\left(V_{T R H}\right)$, one must decide if the condition $\bar{V}_{P}\left(\theta_{i}\right)<V_{T R H}$ is true. Then, it can be concluded that the pedestrian wind comfort is fulfilled. Otherwise, the probability of exceedance of the threshold wind velocity for the respective wind direction $\left(\theta_{i}\right)$ must be calculated using the following eqn:

$$
P\left(\hat{v}_{P}\left(\theta_{i}\right)>v_{T R H}\right)=100 \cdot P\left(\theta_{i}\right) \cdot \exp \left[-\left(\frac{v_{T R H}}{\delta\left(\theta_{i}\right) \cdot c\left(\theta_{i}\right)}\right)^{k\left(\theta_{i}\right)}\right][\%],
$$

where: $P\left(\theta_{i}\right)$ : probability of wind direction; $c\left(\theta_{i}\right), k\left(\theta_{i}\right)$ : parameters of Weibull distribution function (obtained on the basis of data from meteorological station);

$$
\begin{gathered}
\delta\left(\theta_{i}\right)=\eta\left(\theta_{i}\right) \cdot \gamma\left(\theta_{i}\right) \cdot \beta\left(\theta_{i}\right) \\
\eta\left(\theta_{i}\right)=\frac{v_{P}^{T}\left(\theta_{i}\right)}{\bar{v}_{P}\left(\theta_{i}\right)} ; \gamma\left(\theta_{i}\right)=\frac{\bar{v}_{P}\left(\theta_{i}\right)}{\bar{v}_{r e f}\left(\theta_{i}\right)} ; \beta\left(\theta_{i}\right)=\frac{\bar{v}_{r e f}\left(\theta_{i}\right)}{\bar{v}_{M E T}\left(\theta_{i}\right)}
\end{gathered}
$$

where $\eta\left(\theta_{i}\right)$ : time averaging coefficient;

$\gamma\left(\theta_{i}\right)$ : wind velocity amplification coefficient (determined during wind tunnel tests or with CFD methods);

$\beta\left(\theta_{i}\right)$ : transition coefficient. 
The time averaging coefficient $\left(\eta\left(\theta_{i}\right)\right)$ results from different averaging time for wind comfort criteria ( 1 hour in full scale) and for measurement time $(60 \mathrm{~s}$ in model scale, which corresponds to 25 measurements of $10 \mathrm{~min}$ each at full scale). The relationship, which was the basis of calculating this coefficient was determined by Sanz-Andres and Cuerva [6]: $1.05 V^{1 h}=1.0 \bar{V}$, where: $V^{1 h}$ - mean wind velocity in averaging time of 1 hour; $\bar{V}$ - mean wind velocity in averaging time of 10 minutes.

The wind velocity amplification coefficient $\left(\gamma\left(\theta_{i}\right)\right)$ is obtained from wind tunnel tests and shows an increase or decrease of wind action in the measurement point caused by its closest surroundings. It is obtained as the ratio of wind velocity at pedestrian level and wind velocity at a reference point located in the area of undisturbed wind flow in front of the model.

Transition coefficient $\left(\beta\left(\theta_{i}\right)\right)$ enables transfer of the data from the meteorological station, obtained at a reference height of $10 \mathrm{~m}$, in terrain category II to the conditions simulated in the wind tunnel (different terrain category and reference height).

To define the probability of exceedance of threshold wind velocity in one point $(P)$, taking into account $N$ wind directions, one must determine the sum of probabilities:

$$
P_{\text {exc }}\left(\hat{v}_{P}\left(\theta_{i}\right)>v_{T R H}\right)=\sum_{i=1}^{N} 100 \cdot P\left(\theta_{i}\right) \cdot \exp \left[-\left(\frac{v_{T R H}}{\delta\left(\theta_{i}\right) \cdot c\left(\theta_{i}\right)}\right)^{k\left(\theta_{i}\right)}\right][\%] .
$$

Wind tunnel tests are conducted to obtain the coefficient of wind velocity amplification $\left(\gamma\left(\theta_{i}\right)\right)$ with respect to the angle of wind inflow. Subsequently, the probability of the threshold wind velocity exceedance, calculated according to the above procedure, is analysed with respect to the adopted comfort criteria. On the basis of this, the areas of comfortable or uncomfortable wind conditions for pedestrians are indicated, taking into account the type of human activity.

\subsection{Detailed description of test procedure}

Pedestrian wind comfort was assessed at 82 measurement points located in the vicinity of subject building on the ground level. Double-filament hot-wire anemometers were used to measure the modulus of wind velocity in the horizontal plane in the time domain. The mean wind velocity and GEM velocity at the pedestrian height $(1.5 \div 2.0 \mathrm{~m}$ in nature $)$ for the respective angle of wind inflow $\left(\bar{V}_{P}\left(\theta_{i}\right)\right)$ was determined in each measurement point located in the analysed area. Simultaneously, reference velocity $\left(V_{r e f}\right)$ was measured at the reference height $\left(z_{\text {ref }}=470 \mathrm{~mm}\right)$ in the area of undisturbed wind flow in the front of the model. This velocity was maintained at a level of about $5 \mathrm{~m} / \mathrm{s}$, as the most convenient range for the hot-wire anemometers used. Vertical wind velocity and turbulence intensity profiles are presented in Fig. 6. The sampling frequency was $1250 \mathrm{~Hz}$ and the measurement time was $60 \mathrm{~s}$. This corresponds to 25 measurements of 10 minutes each at the full scale. Each period of $3 \mathrm{~s}$, used for extreme value analysis, consists of 15 measuring samples. Investigations were carried out for 18 angles of wind inflow at $20^{\circ}$ intervals (Fig. 7).

The Lawson wind comfort criteria have been used to assess the proposed development's pedestrian wind comfort. These criteria belong to group A as described above in the text. There is a fixed threshold of probability of wind velocity exceedance. The Lawson criteria are considered as the industry standard in the United Kingdom. Details of the London Docklands Development Corporation (LDDC) variant of the Lawson criteria which was used herein are summarized in Table 1. This variant of the Lawson criteria is the most conservative one and is taken directly from RWDI [7]. 


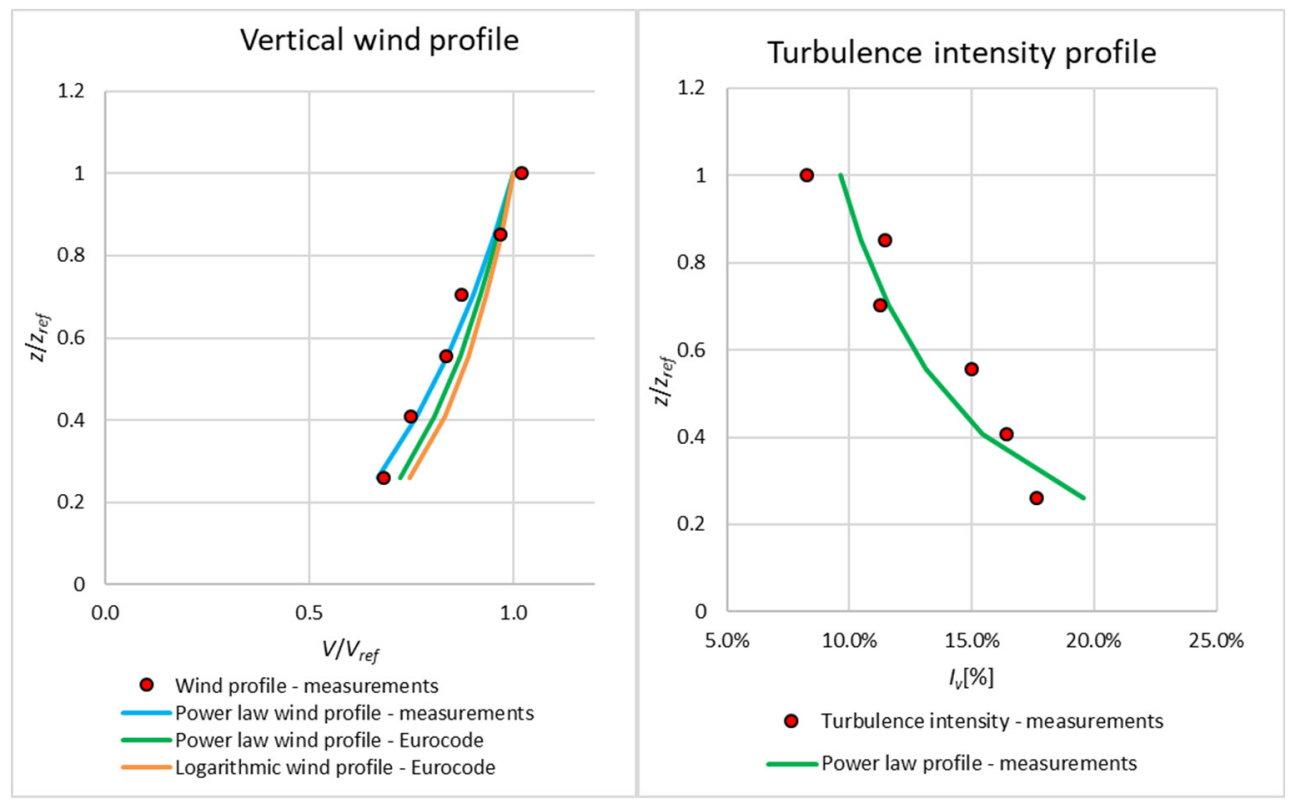

Figure 6: Vertical wind velocity and turbulence intensity profiles.

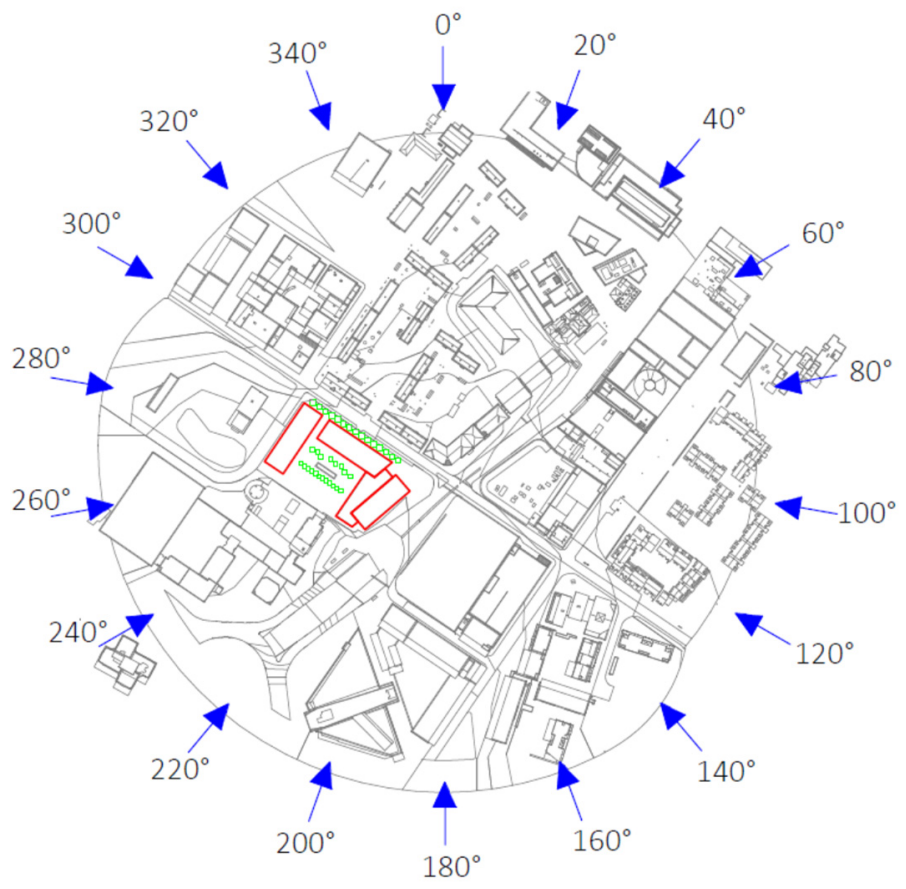

Figure 7: Wind directions investigated during wind tunnel tests - The Square building complex is marked in red. 
Table 1: Lawson LDDC wind comfort criteria.

\begin{tabular}{|c|c|c|l|}
\hline \multicolumn{4}{|c|}{ Lawson Comfort Criteria (LDDC) } \\
\hline Pedestrian activity & $P_{T R H}$ & $v_{T R H}$ & \multicolumn{1}{c|}{ Description } \\
\hline Frequent sitting & \multirow{2}{*}{$5 \%$} & $2.5 \mathrm{~m} / \mathrm{s}$ & $\begin{array}{l}\text { Acceptable for frequent outdoor sitting } \\
\text { use, such as café or restaurant outdoor } \\
\text { tables }\end{array}$ \\
\cline { 4 - 5 } Occasional sitting & \multirow{2}{*}{$\begin{array}{c}5 \% \\
\text { Standing }\end{array}$} & $4 \mathrm{~m} / \mathrm{s}$ & $\begin{array}{l}\text { Acceptable for occasional outdoor } \\
\text { sitting use, such as balconies and } \\
\text { terraces or park benches }\end{array}$ \\
\cline { 4 - 5 } Walking & $6 \mathrm{~m} / \mathrm{s}$ & $\begin{array}{l}\text { Gentle breezes suitable for building } \\
\text { entrances or bus stops }\end{array}$ \\
\cline { 4 - 5 } Uncomfortable & $8 \mathrm{~m} / \mathrm{s}$ & $\begin{array}{l}\text { Relatively high speeds tolerable for } \\
\text { someone walking or cycling (transit) }\end{array}$ \\
\cline { 4 - 5 } & & $>8 \mathrm{~m} / \mathrm{s}$ & $\begin{array}{l}\text { Not comfortable for regular pedestrian } \\
\text { access }\end{array}$ \\
\hline
\end{tabular}

\section{TEST RESULTS}

Test results are shown in the map (Fig. 8.), with each measuring location colour-coded to its respective criteria at a given scenario according to Table 1. Only annual results are shown in the paper, seasonal results are provided within the presentation.

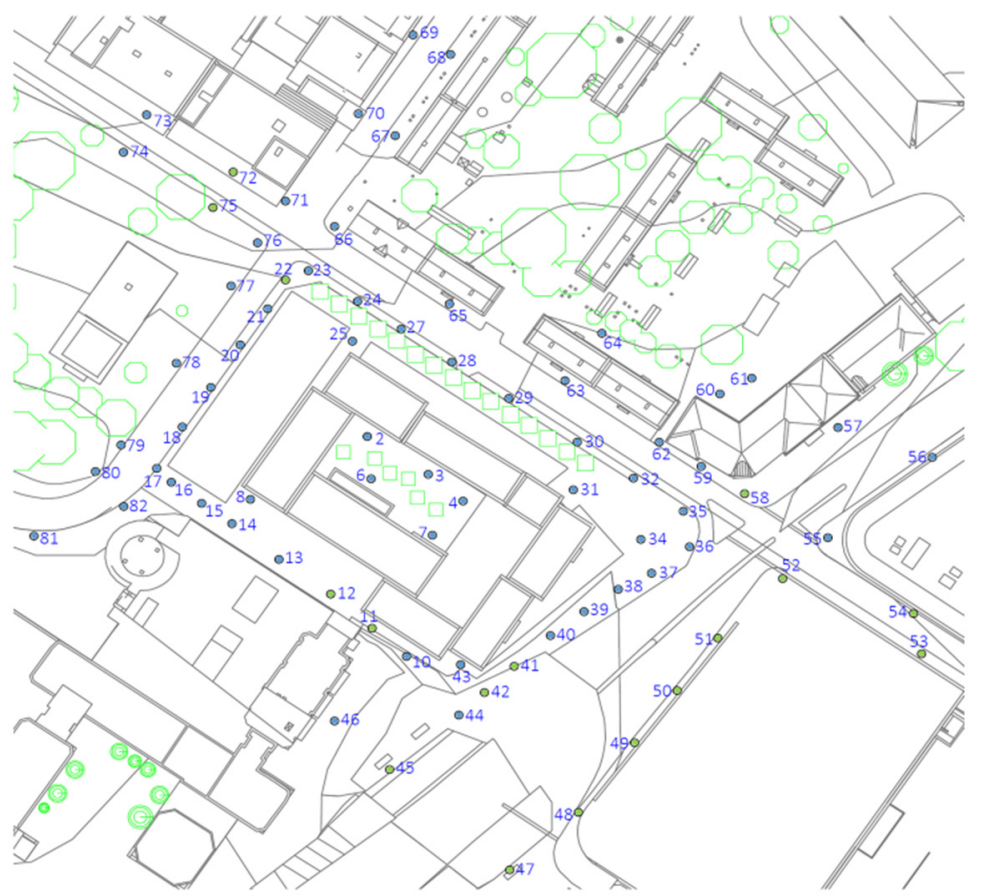

(a)

Figure 8: Model test results of pedestrian wind comfort. (a) Scenario 1; (b) Scenario 2; and (c) Scenario 3. 


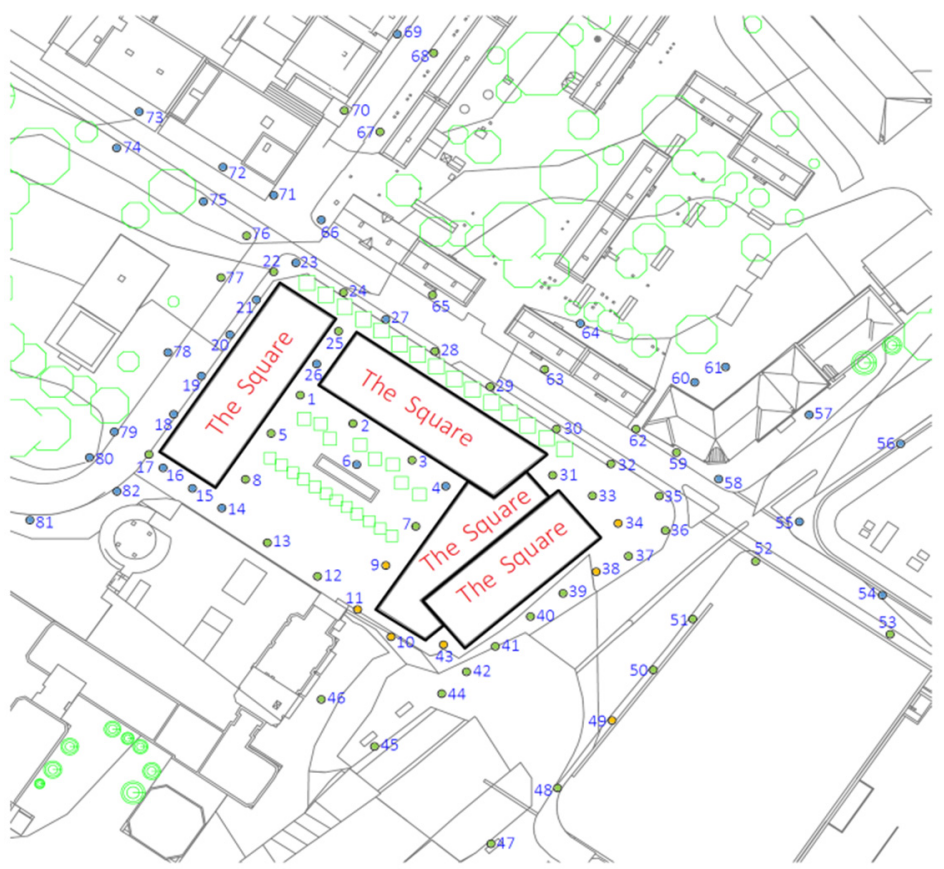

(b)

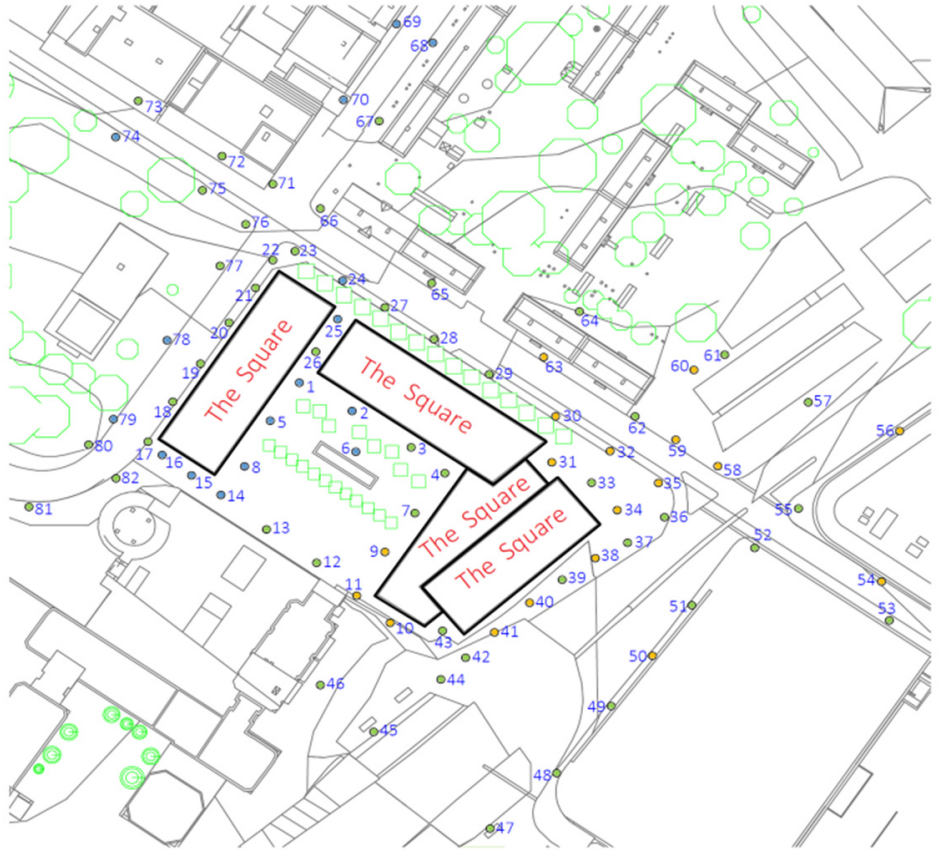

(c)

Figure 8: Continued. 


\section{CONCLUSIONS}

In general, pedestrian wind comfort conditions at the surroundings of The Square building complex are favourable for people. At none of the measuring locations the conditions can be considered as uncomfortable.

For Scenario 2, only 7 measuring locations are marked as "suitable only for pedestrian transit/walking". These locations are points 34, 38 and 49 (also point 42 in case of winter) located at the pavements alongside Broad Street and points 9, 11, 10 and 43 located around the south and south-west façades of Building A of The Square complex. It is advised not to locate main building entrances around these locations or put some wind mitigation measures if the entrances there are necessary (for example recess passages or pillars which will shield the entrances from the wind, also automated doors with small vestibule chambers are advised to minimise any potential shock effect for people leaving the building). During summertime, "suitable only for pedestrian transit/walking" conditions are reduced to points 43 and 49 only.

The remaining measuring locations are suitable either for standing or occasional outdoor sitting, which classifies them as suitable for the desired use. It should be especially noticed that points 1-7, which are at the courtyard of The Square complex where potential leisure zones might be located, are suitable for outdoor sitting in summer, with points 4 and 6 being suitable for outdoor sitting during whole year.

Furthermore, the wind comfort conditions for building entrances are fulfilled at any locations around Buildings A, B and C, with the exceptions of south and south-west façades of Building A mentioned above.

As the buildings which are currently located at the site are low rise and form a closed court, the existing wind conditions at the surroundings of the site are very calm and comfortable for pedestrians, with all locations indicated as suitable for either standing of outdoor sitting. Points 2 and 6 even are suitable for frequent outdoor sitting during summertime. It should be noted, however, that points 2, 3, 4, 6 and 7 are located inside the courtyard surrounded by the buildings which completely shields them from the wind.

The largest deterioration caused by The Square complex can be noticed at points located at the pavements alongside Broad Street - for points 10, 34, 38 and 43 wind comfort conditions drop from "suitable for occasional outdoor sitting" to "suitable only for pedestrian transit/walking". This might be caused by the close vicinity of the high-rise Building A of The Square complex and is typical for such buildings. The adverse conditions at these locations can be attributed to potential downdrafts or vortex creation in the aerodynamic wake of this building. Moreover, the winds from south-west directions are prevailing at the site's location, which leads to accumulation of negative wind effects around the southern façade of the building and alongside its south-east longitudinal façade, parallel to the strongest winds paths.

It should be noted that during winter and summer, these differences are not as apparent between the two investigated scenarios. Furthermore, there are 4 measuring locations where the wind comfort conditions are more favourable in the Scenario 2, with The Square building. These locations are points 54 and 58 (intersection of Broad Street and Ryland Street), 72 and 75 (intersection of Grosvernor Street and Ryland Street). The same effect can be noticed on nearby points $56,72,73$ and 75 for winter and points 51,52 and 72 for summer. This can be attributed to the shielding effect of The Square building complex, especially the high-rise Building A, on these locations.

Measuring locations 44, 45 and 46 are located around the "Five Ways Shopping Centre" bus stop in the vicinity of the site. During all the yearly and seasonal alternatives investigated for Scenario 2, these locations are suitable for standing, which is the wind comfort condition desired at bus stops. 
The joint impact on pedestrian wind comfort from The Square and other approved developments is mostly manifested at and around Ryland Street. This is caused by two of the high-rise buildings - The Square building A and 100 Broad Street - standing in a close proximity of each other. There seems to be a channelling effect present at Ryland Street between these two buildings and perhaps wind amplification caused by downdrafting from either of these two tall buildings. Points $30,31,32,34,35$ which are at the sidewalk by The Square and points 58, 59, 60, 63 on the other side of the street (near 100 Broad Street) are affected by this joint impact and are only suitable for walking. These points are mostly located at the sidewalks. Also points 50, 54 and 56, as well as points 38, 40, 41 located by The Square building A by Broad Street and points 9, 10 and 11 which are located at the courtyard of The Square complex are suitable only for walking. These points also are located at pedestrian transit routes. It should be noted that during winter, the number of locations suitable for walking only (located on pedestrian transit routes) is even larger.

A large number of points inside the courtyard of The Square complex $(1,2,5,6,8$ and 14) can still be considered suitable for occasional sitting. It can be observed that for some of the locations inside the courtyard, the conditions are now even more comfortable than for Scenario 2.

The measurement error in such tests has to be estimated basing on the following variables:

- Precision of the measuring equipment (in the case of hot-wire anemometers, it is at the level of $5-10 \%$ );

- Model precision (buildings shapes, accuracy on wind directions);

- Blockage effect (mostly significant on the edges of the whole model - in case where the building is in the centre, this effect does not affect results significantly);

- The precision level of re-creating the turbulence.

On the summary of all these factors, the measuring error can be estimated at about $10-15 \%$, which is sufficient for engineering approaches.

\section{ACKNOWLEDGEMENTS}

Wind tunnel model tests presented herein are a result of commissioned work conducted for 2020 Living Ltd. - developer and in cooperation with consulting engineers - Design2e.

\section{REFERENCES}

[1] Flaga, A., Pistol, A., Krajewski, P. \& Flaga, Ł., Cold Regions Science and Technology Aerodynamic and aeroelastic wind tunnel model tests of overhead power lines in triangular configuration under different icing conditions. Cold Regions Science and Technology, 170, pp. 102919, 2020. https://doi.org/10.1016/j.coldregions.2019.102919.

[2] Holger Koss, H., On differences and similarities of applied wind comfort criteria. Journal of Wind Engineering and Industrial Aerodynamics, 94(11), pp. 781-797, 2006. https://doi.org/10.1016/j.jweia.2006.06.005.

[3] Ratcliff, M.A. \& Peterka, J.A., Comparison of pedestrian wind acceptability criteria. Journal of Wind Engineering and Industrial Aerodynamics, 36, pp. 791-800, 1990. https://doi.org/10.1016/0167-6105(90)90076-O.

[4] Flaga, A., Wind Engineering. Fundamentals and Applications, Arkady: Warsaw 2008. (In Polish.) 
[5] Flaga, A., Kocoń, A., Kłaput, R. \& Bosak, G., The environmental effects of aerodynamic interference between two closely positioned irregular high buildings. Journal of Wind Engineering and Industrial Aerodynamics, 180, pp. 276-287, 2018.

[6] Sanz-Andres, A. \& Cuerva, A., Pedestrian wind comfort: Feasibility study of criteria homogenisation. Journal of Wind Engineering and Industrial Aerodynamics, 94(11), pp. 799-813, 2006. https://doi.org/10.1016/j.jweia.2006.06.004.

[7] RWDI, Wind Microclimate Guidelines for Developments in the City of London, 2019. 